\title{
Review of: "Role of Climatic Factors In The Toxicity of Fipronil Toward Earthworms In Two Tropical Soils: Effects of Increased Temperature And Reduced Soil Moisture Content"
}

\author{
Diego Ballestero
}

Potential competing interests: The author(s) declared that no potential competing interests exist.

In this article the authors describe the toxicity of the fipronil compound in different soils and at different temperatures. It is a current work and in line with the global problem of the increase in terrestrial temperature.

The article is well written and explained. The authors are very clear describing the methodology used and the results are very well justified based on the results obtained.

However, there are things that have not been considered and that should have been taken into account when writing the article.

The authors mention a commercial product for fipronil with a concentration of $250 \mathrm{~g} / \mathrm{L}$, it is understood that the solvent is not water, since the solubility of fipronil in water is $1.9 \mathrm{~g} / \mathrm{ml}$. [1] This concentration implies the use of another solvent and therefore, if a control with distilled water has been prepared in the tests it would not be the correct thing to do, it should be done with the solvent in which fipronil is dissolved.

Fipronil has been reported to have quite erratic dissolution behavior over time and this is accentuated with changes in temperature. The consequences give rise to a greater or lesser solubility in distilled water or in this case in artificial soil water, therefore the worms may be exposed to concentrations different from that expected, especially in such a long period of time [2,3]. It is true that the authors estimate the concentration in the soil by means of LC-MS, but in such a long period of time the variations in the concentration of fipronil can influence the reproductive cycle of the worms, therefore the verification of the real concentration of fipronil on the ground over time would be recommended.

Although it is a minor problem, the authors do not mention why they have selected those 20-25-27 temperature ranges. Wouldn't it be more logical to go to $30 \stackrel{\circ}{ } \mathrm{C}$ ?

[1] Pudchem, https://pubchem.ncbi.nIm.nih.gov/compound/Fipronil.

[2] J.V. Headley, J. Gandrass, J. Kuballa, K.M. Peru, Y.L. Gong, Rates of sorption and partitioning of contaminants in river biofilm, Environmental Science \& Technology 32(24) (1998) 3968-3973.

[3] A.D. Goff, P. Saranjampour, L.M. Ryana, M.L. Hladik, J.A. Covi, K.L. Armbrust, S.M. Brander, The effects of fipronil and the photodegradation product fipronil desulfinyl on growth and gene expression in juvenile blue crabs, Callinectes sapidus, at different salinities, Aquatic Toxicology 186 (2017) 96-104. 
